\title{
Correction to: Towards planning of osteotomy around the knee with quantitative inclusion of the adduction moment: a biomechanical approach
}

Margit Biehl ${ }^{1^{*}}\left(\mathbb{0}\right.$, Philipp Damm²0, Adam Trepczynski ${ }^{2}$, Stefan Preiss ${ }^{3}$ and Gian Max Salzmann 3,4

Correction to: J Exp Ortop 8:39, (2021).

https://doi.org/10.1186/s40634-021-00324-3

In the original publication of this article [1], Additional files 1, 2 and 3 were incorrect. The formula in Additional file 1 must include the number " 0.349 " instead of " 0.342 ". Incorrect files have been replaced. The original article has been corrected.

\section{Author details}

${ }^{1}$ Fraunhofer Institute for Biomedical Engineering IBMT, Joseph-von-Fraunhofer-Weg 1, 66280 Sulzbach, Germany. ${ }^{2}$ Charité-Universitätsmedizin Berlin, corporate member of Freie Universität Berlin, Humboldt-Universität Zu Berlin and Berlin Institute of Health, Berlin, Germany. ${ }^{3}$ Lower Extremity Orthopaedics,
Musculoskeletal Center, Schulthess Clinic, Zurich, Switzerland. ${ }^{4}$ Gelenkzentrum Rhein-Main, Wiesbaden, Germany.

Published online: 24 June 2021

\section{Reference}

1. Biehl M, Damm P, Trepczynski A et al (2021) Towards planning of osteotomy around the knee with quantitative inclusion of the adduction moment: a biomechanical approach. J Exp Ortop 8:39. https://doi.org/10. 1186/s40634-021-00324-3

${ }^{*}$ Correspondence: margit.biehl@ibmt.fraunhofer.de

${ }^{1}$ Fraunhofer Institute for Biomedical Engineering IBMT,

Joseph-von-Fraunhofer-Weg 1, 66280 Sulzbach, Germany

Full list of author information is available at the end of the article original author(s) and the source, provide a link to the Creative Commons licence, and indicate if changes were made. The images or other third party material in this article are included in the article's Creative Commons licence, unless indicated otherwise in a credit line to the material. If material is not included in the article's Creative Commons licence and your intended use is not permitted by statutory regulation or exceeds the permitted use, you will need to obtain permission directly from the copyright holder. To view a copy of this licence, visit http://creativecommons.org/licenses/by/4.0/. 